\title{
Estimates of Age-Specific Mortality Rates from Sequential Cross-Sectional Data in Malawi
}

\author{
Henry V. Doctor \\ Mailman School of Public Health, Columbia University, 60 Haven Avenue, Suite B2, \\ New York, NY 10032, USA \\ Correspondence should be addressed to Henry V. Doctor, hvd2105@columbia.edu
}

Received 1 November 2011; Accepted 17 January 2012

Academic Editor: Kathryn Kost

Copyright ( 2012 Henry V. Doctor. This is an open access article distributed under the Creative Commons Attribution License, which permits unrestricted use, distribution, and reproduction in any medium, provided the original work is properly cited.

This paper uses a method for estimating age-specific event rates for adults (15-49 years) in Malawi between 1977 and 1998 . This method, which is based on the development of unstable populations, is similar to the "variable-r" methods. Data from Malawi demonstrate mortality reduction nearly for all age groups between 1977 and 1987 for males whereas for females the reduction was observed for age groups 15-19 and 40-44. Contrary to this finding, the 1987-1998 intercensal period shows that mortality increased at a higher rate in the ages 20 and above for males than females. However, the increase for the females is much higher in the 1987-1998 intercensal period than in the 1977-1987 intercensal period. These findings may be related to the onset and effect of the AIDS epidemic. Implications for future research are discussed.

\section{Introduction}

The availability of cross-sectional data to demographers provides an opportunity to learn about event rates by comparing changes between the two periods of interest. In the case of Malawi, the available census data between 1987 and 1998 can be used to investigate, among other things, agespecific mortality rates over the 1987-1998 inter-ensal period for males and females. This means that we can compare the "before" and "after" schedules of mortality. In this case, the "before" schedule may be associated with the 1987 census as the period characterized by low mortality compared with the "after" schedule as this period is before 1998 is characterized by high mortality.

Schmertmann [1] provides a simple formula for estimating event rates from cross sectional data. The formula may also be used in general applications such as learning about young adults' moves in and out of parental homes by comparing age schedules of the proportion living with parents from consecutive censuses or to study prevalence of smoking by age. Thus, rates can be inferred from crosssections in many fields.

\section{Background}

Malawi lies in the eastern and southern African "AIDSbelt" with a population of about 10 million according to the 1998 census. (The estimated population in 2011 was 15 million (http://www.countrystat.org/mwi/en; accessed on 1 November 2011).) Malawi is a poor country, overwhelmingly agrarian, and about $90 \%$ of the population reside in rural areas [2]. Malawi's agrarian economy accounts for more than $90 \%$ of its export earnings, contributes $45 \%$ of GDP, and supports $90 \%$ of the population. The country's export trade is dominated by tobacco, tea, cotton, coffee, and sugar. In general, Malawi is very poor, even by African standards: its gross national income per capita was estimated at 190 USD in 2002, in comparison to a sub-Saharan African mean of 480 USD [3].

According to the Malawi 2000 Demographic and Health Survey (DHS), the country's total fertility rate was estimated at 5.9; life expectancy at birth was estimated at 40 for males and 42 for females; and GNP per capita was about 190 USD [3]. The HIV/AIDS prevalence was estimated to be $15 \%$ for adults aged from 15 to 49 [4]. In addition, Malawi is one of 
Table 1: Age-specific death rates by sex: Malawi 1977, 1987, and 1998 censuses.

\begin{tabular}{|c|c|c|c|c|c|c|}
\hline \multirow{2}{*}{ Age group } & \multicolumn{2}{|c|}{1977} & \multicolumn{2}{|c|}{1987} & \multicolumn{2}{|c|}{1998} \\
\hline & Males & Females & Males & Females & Males & Females \\
\hline $10-14$ & 12.9 & 12.7 & 6.2 & 5.4 & 8.6 & 8.3 \\
\hline $15-19$ & 6.3 & 6.3 & 2.4 & 2.9 & 5.1 & 5.3 \\
\hline $20-24$ & 6.5 & 6.3 & 4.0 & 5.3 & 7.1 & 6.5 \\
\hline $25-29$ & 8.4 & 6.9 & 5.3 & 7.0 & 11.8 & 8.4 \\
\hline $30-34$ & 8.9 & 7.5 & 5.3 & 6.9 & 12.5 & 10.9 \\
\hline $35-39$ & 9.5 & 8.7 & 5.4 & 7.0 & 13.4 & 12.7 \\
\hline $40-44$ & 10.8 & 10.0 & 6.0 & 7.6 & 15.3 & 14.6 \\
\hline $45-49$ & 13.0 & 11.1 & 7.0 & 8.6 & 18.5 & 15.8 \\
\hline $50-54$ & 15.7 & 12.2 & 8.8 & 10.3 & 22.2 & 17.1 \\
\hline
\end{tabular}

the countries hit hard by the AIDS epidemic with substantial differences between the urban and rural areas [5]. It has been estimated that AIDS led to a reduction in overall life expectancy at birth during the 1990s. For example, during the 1990s in Malawi, it was estimated that life expectancy at birth for females dropped from 51 years to 46 years, whereas for males, the level dropped from 47 years to 45 years [6].

Regional variations in adult survival are substantial. The northern region has lower mortality compared to the central and southern regions. Bicego [7] showed that adults (15-49) in the northern region had much better survival prospects (crude mortality rate was four per 1,000 person years lived) than did adults in the central and southern regions (crude mortality rate was seven per 1,000 person years lived). (These mortality rates are based on the period 0-6 years prior to the Malawi 1992 DHS, that is, the period from 1986 to 1992.) This finding is consistent with the patterns of social development shown by education, employment levels, and differentials in childhood mortality. (For example, Osmond and Manda [8] and Baker [9] found regional differentials in infant and child mortality with children in northern region having better survival advantage than those in the central and southern regions. More recent estimates on Malawi are available at http://go.worldbank.org/9VBQH68ZR0. The background statistics have been presented closer to the endpoint year of the study to align the results with the prevailing situation.)

Against this background, this paper examines adult mortality rates in Malawi between 1977 and 1998 using life tables calculated based on census data from 1977, 1987, and 1998. Thus, the goal of this paper is to estimate age-specific mortality rates for the intercensal periods. It should be noted that most of the mortality statistics from the census are provided at national level, and regional- or district-specific analyses are not available.

\section{Methods}

Schmertmann [1] presents the first function $V(a, t)$ as a population value of interest at exact age $a$ and time $t$ (e.g., the proportion of women using contraceptives, the proportion of young men currently smoking, or the average number of previous arrests for drunk driving). Demographers in their work usually observe average values for discrete age groups, denoted as $n V x(t)$ for age group $x$ to $x+n$ at time $t$, and must interpolate to find $V$ values at exact ages. (Schmertmann [1] discusses various ways of interpolation in his paper such as moving average and splines. Readers should see Schmertmann's work for more technical aspects of the method.)

The second function presented is $\delta(a, t)$, which is the focus of the method. This function represents the net, additive, and intracohort change in $V$ per unit of time. The $\delta$ is a rate in the sense that it measures events per year, day, or minute, but not in the sense of events per unit of exposure. The $V(a, t)$ can be thought of as representing a cumulative sum of changes within a cohort between birth, age $a$, and $\delta(a, t)$ as representing the rate at which cohort $V$ changes per unit of time. The $V$ values may change in both directions though some events such that fertility may increase mean cohort parity. The value $\delta$ measures the net addition to $V$ per unit of time.

This method is described as arising from the formal mathematics of unstable populations and is similar in spirit to "variable-r" methods developed by Preston, Coale, and others [10]. The advantage of this method is that it does not require specialized computer programming or iterative calculations, and event rates can be estimated using simple spreadsheet calculations. Therefore, this paper presents agespecific mortality rates for 15-49-year-old Malawians over the intercensal periods 1977-1987 and 1987-1998. For this period, the available data are age-specific mortality rates, by five-year age group from life tables. For the ages between 10 and 54, the $V$ data (values) (although the interest is to estimate mortality rates of 15-49 years old, ages between 10 and 54 are presented for methodological reasons-these values are used for interpolation) from the 1977, 1987, and 1998 censuses by sex are given in Table 1 . This information is useful because it provides one of the ways of assessing the recent direction of adult mortality in Malawi.

Table 1 shows that, overall and for both sexes, there was a decline in age-specific mortality rates between 1977 and 1987 and an increase between 1987 and 1998. For example, male death rates between ages 10-14 declined from a high 
of 12.9 per 1,000 population in 1977 to a low of 6.2 per 1,000 population in 1987 and further increased to 8.6 per 1,000 population in 1998. For females, in age group 10-14 death rates declined from 12.7 per 1,000 population in 1977 to 5.4 per 1,000 population in 1987 and increased to 8.3 per 1,000 population in 1998. Although the magnitude in declines and increases between 1977-1987 and 1987-1998 intercensal periods varies for specific age groups, the trend is the same, that is, mortality decreased between 1977 and 1987 and increased between 1987 and 1998.

The Schmertmann method to estimate (mortality) rates between cross-sections has two basic steps. First, we need to interpolate within each cross-sectional schedule to estimate mean $V$ values at the "four" corners of the age-period cell of interest. In Table 1 , the corners are at $(a, t)$ combinations $(15,1977),(20,1977),(15,1987)$, and $(20,1987)$ for males and females, respectively. Similarly, this can be done for the period between 1987 and 1998, that is, $(15,1987)$, $(20,1987),(15,1998)$, and $(20,1998)$ for both sexes and the other ages as well. If we use simple averages which Schmertmann uses in his method, the interpolated 1977 mean age-specific death rate for males at exact age 15 is then the average of the age-specific death rates in the 10-14 and 15-19 age groups: $(12.9+6.3) / 2=9.6$. The values used for calculation are from Table 1 and the value 9.6 appears in Table 2 under "1977 Males" for exact age 15. Using this approach, we get interpolated mean age-specific death rates for the remaining exact ages in Table 2. Intuitively, because the interpolated mean age-specific death rates in Table 2 are calculated from Table 1, the trend between 1977-1987 and 1987-1998 intercensal periods is the same.

The second step involves applying an arithmetic formula to the four "corner values" to estimate the rate. Schmertmann [1] notes that the estimation formula varies with the width of the age and time intervals. For example, in this case, the width of the age for the 1977-1987 and 1987-1998 intercensal periods is five, whereas the time interval is 10 and 11 respectively. In general, the arithmetic formula used is

$\delta[0, T] \approx\left(\frac{1}{2 n}+\frac{1}{2 T}\right)\left[\mathbf{V}_{\mathbf{C}}-\mathbf{V}_{\mathbf{A}}\right]+\left(\frac{1}{2 n}-\frac{1}{2 T}\right)\left[\mathbf{V}_{\mathbf{B}}-\mathbf{V}_{\mathbf{D}}\right]$,

where the left-hand side is the rate at which cohort $V$ changes between time 0 and $T, n$ is the width of the age interval, $T$ is the length of the interval (10 for 1977-1987 and 11 for 19871998 intercensal periods), $\mathbf{V}_{\mathbf{C}}-\mathbf{V}_{\mathbf{A}}$ and $\mathbf{V}_{\mathbf{B}}-\mathbf{V}_{\mathbf{D}}$ are the differences between the four "corner values." Schmertmann [1] calls this formula the "criss cross formula" because it uses differences of the values of $V$. This formula is used to generate the rates in Table 3.

Applying the "criss cross formula" to the Malawi data for males during the 1977-1987 intercensal period for age group $15-19$ yields the following value: ${ }_{5} f_{15}[1977-1987] \approx$ 0.15 [3.2-9.6] $+0.05[\mathbf{6 . 4 - 4 . 3}] \approx \mathbf{- 0 . 8 5 5}$.

Similarly, the other values in Table 3 are calculated in a similar manner. The value of 0.855 appears in Table 3 for the cell of age group 15-19, in 1977-1987, males. These estimates are quite consistent with those in Table 1 . The negative values in Table 3 indicate the net reduction in death rates, and the

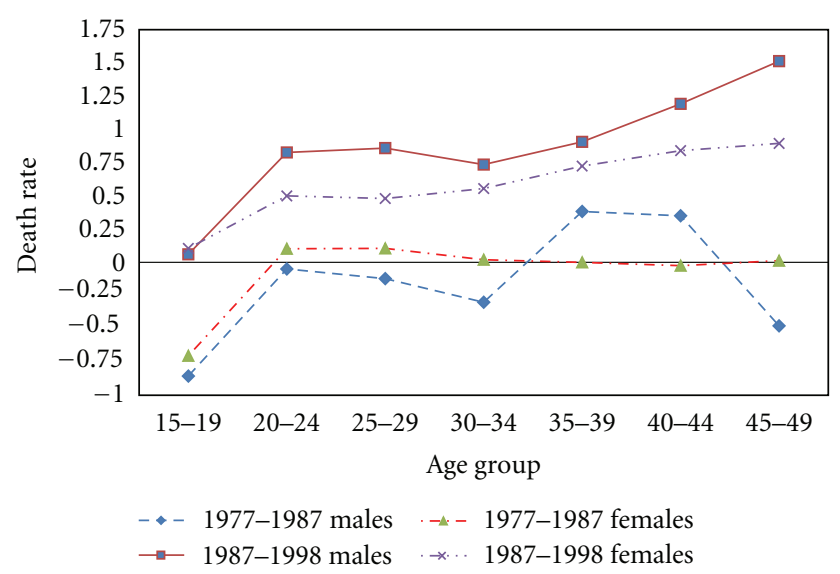

Figure 1: Age-specific death rates: Malawi, 1977-1987 and 19871998 intercensal periods.

positive values indicate the net increase in death rates over the intercensal period(s). As an example, the death rate in the 15-19 age interval over the 1977-1987 intercensal period for males $(-0.855)$ suggests that the net death rate was hugeapproximately 855 per 1,000 per year at ages $15-19$. Some of this reduction might have been due to higher survival in this age group. The results in Table 3 show that males during 1987-1998 have positive values compared to 19771987 where they have negative and positive values.

To make a graphical version of these estimates in Table 3 , I plot Figure 1 which shows that the "criss cross" method produces noisier estimates after the age group 30-34 for males during the 1977-1987 intercensal period, but in general, the linear approximations from (1) show that death rates have been higher and increasing for the 1987-1998 intercensal period for both sexes. The increase is larger for ages 35 and above and for males than females.

As Schmertmann [1] puts it, "simulation experiments and real-world examples suggest that the linear approximation or "criss cross" method for estimating intracohort change from sequential cross-sections will work well in many applications" (p. 308). In general, linear approximations are simple, fast, and accurate. Further, Schmertmann [1] found that results from linear approximation are comparable to those generated by more complex methods. This method has also loose data requirements. For example, we only need data to interpolate within each of the two period schedules to estimate $V$ values at exact ages.

\section{Discussion}

This paper examined the age-specific mortality rates for males and females during the 1977-1987 and 1987-1998 intercensal periods in Malawi. Applying a method developed by Schmertmann [1], the results showed that there was mortality reduction nearly for all age groups between 1977 and 1987 for males, whereas for females the reduction was observed for age groups $15-19$ and 40-44. That is, while males enjoyed better survival, females were at a disadvantage. 
TABLe 2: Interpolated mean age-specific death rates by sex: Malawi 1977, 1987, and 1998 censuses.

\begin{tabular}{|c|c|c|c|c|c|c|}
\hline \multirow{2}{*}{ Exact age } & \multicolumn{2}{|c|}{1977} & \multicolumn{2}{|c|}{1987} & \multicolumn{2}{|c|}{1998} \\
\hline & Males & Females & Males & Females & Males & Females \\
\hline 15 & 9.6 & 9.5 & 4.3 & 4.2 & 6.9 & 6.8 \\
\hline 20 & 6.4 & 6.3 & 3.2 & 4.1 & 6.1 & 5.9 \\
\hline 25 & 7.5 & 6.6 & 4.7 & 6.2 & 9.5 & 7.5 \\
\hline 30 & 8.7 & 7.2 & 5.3 & 7.0 & 12.2 & 9.7 \\
\hline 35 & 9.2 & 8.1 & 5.4 & 7.0 & 13.0 & 11.8 \\
\hline 40 & 10.2 & 9.4 & 10.2 & 7.3 & 14.4 & 13.7 \\
\hline 45 & 11.9 & 10.6 & 11.9 & 8.1 & 16.9 & 15.2 \\
\hline 50 & 14.4 & 11.7 & 7.9 & 9.5 & 20.4 & 16.5 \\
\hline
\end{tabular}

TABLE 3: Estimated mortality rates, by sex, for Malawi 1977-1987 and 1987-1998 intercensal periods.

\begin{tabular}{|c|c|c|c|c|}
\hline \multirow{2}{*}{ Age group } & 1977-1987 & 1987-1998 & 1977-1987 & 1987-1998 \\
\hline & Males & Males & Females & Females \\
\hline $15-19$ & -0.8550 & 0.0603 & -0.7025 & 0.1053 \\
\hline $20-24$ & -0.0500 & 0.8265 & 0.1025 & 0.4995 \\
\hline $25-29$ & -0.1225 & 0.8593 & 0.1050 & 0.4800 \\
\hline $30-34$ & -0.3000 & 0.7353 & 0.0200 & 0.5548 \\
\hline $35-39$ & 0.3825 & 0.9063 & 0.0000 & 0.7240 \\
\hline $40-44$ & 0.3500 & 1.1923 & -0.0250 & 0.8403 \\
\hline $45-49$ & -0.4775 & 1.5133 & 0.0125 & 0.8945 \\
\hline
\end{tabular}

This differential may be related to maternal mortality in the childbearing age groups. Contrary to this finding, the 19871998 intercensal period shows that mortality increased at a higher rate in the age of 20 and above for males than females. However, the increase for the females is much higher for the 1987-98 intercensal period than the 1977-87 intercensal period.

In Malawi, the most common and appealing explanation for these differences in mortality rates between 1977 and 1998 is the effect of HIV/AIDS, which is estimated to have been very high in the late 1990s. In fact, the first AIDS case was reported to the Ministry of Health in 1985 [11], and infection rates increased rapidly during the late 1990s. The HIV /AIDS prevalence for adults (15-49) was estimated at $15 \%$ [4]. In addition, recent studies in developing countries discuss many factors contributing to increased mortality. For example, poverty is a determinant of poor general health status in both adults as well as children. In Malawi, a large proportion of adults (especially women) as well as children suffer from chronic and severe malnutrition [12]. Since the 1980s, Malawi has experienced a decline in the quality of basic education although enrolment and literacy levels have gone up. In addition, health services have become unaffordable to many people leading to poor health [12].

Results from the 1992 and 2000 Malawi DHS showed that at the national level there had been little or no improvement in the use of maternal services in Malawi during the 1990s. It is also reasonable to expect that this situation was the same between 1977 and 1987 hence the increase in female death rates compared to those of men. Other explanations point to the economic, social, and cultural differences in Malawi. About $65 \%$ of people are living below the poverty line, and there is also a high prevalence of HIV/AIDS. The relative timing and exposure to these factors may have an impact on age-specific mortality.

Although we attribute these changes to AIDS-related mortality, unless we have cause-specific mortality data in Malawi, it is very difficult to explain the observed age patterns of mortality. Future analysis of intercensal differentials in death rates will be meaningful with the availability of cause of death data. That is, it would be better to estimate differences in age-specific mortality rates by calculating the contribution of various causes of death. This paper has, therefore, presented a necessary step in understanding the dynamics of intercensal mortality.

\section{References}

[1] C. P. Schmertmann, "A simple method for estimating agespecific rates from sequential cross sections," Demography, vol. 39, no. 4, pp. 287-310, 2002.

[2] Malawi National Statistical Office, 1998 Malawi Population and Housing Census Analytical Report (Publishable Version II), National Statistical Office, Zomba, Malawi, 2002.

[3] World Bank, World Development Report 2000/2001: Attacking Poverty, The World Bank Group, Washington, DC, USA, 2002.

[4] UNAIDS, [The Joint UN Programme on HIV/A IDS] and WHO [World Health Organization], The Global AIDS Epidemic Update, WHO, Geneva, Switzerland, 2003. 
[5] United States Bureau of the Census, Recent HIV Seroprevalence Levels by Country: June 2001, Health Studies Branch, Center for International Research, Washington, DC, USA, 2001.

[6] G. C. Matchaya, "Trends in life expectancy and the macroeconomy in Malawi," Malawi Medical Journal, vol. 19, no. 4, pp. 154-158, 2007.

[7] G. Bicego, "Estimati ng adult mortality rates in the context of the AIDS epidemic in sub-Saharan Africa: analysis of DHS sibling histories," Health Transition Review, vol. 7, supplement 2, pp. 7-22, 1997.

[8] S. Osmond and M. Manda, "Unobserved family and community effects on infant mortality in Malawi," Genus, vol. 54, no. 1-2, pp. 143-164, 1998.

[9] K. R. Baker, Differentials in Child Mortality in Malawi, University of Pennsylvania Population Studies Center, 1999.

[10] S. H. Preston, P. Heuveline, and M. Guillot, Demography: Measuring and Modeling Population Processes, Blackwell, Oxford, UK, 2001

[11] P. J. O. Olsgard, Policy formation: HIV/AIDS in Kenya and Malawi, Ph.D. dissertation, University of Denver, 1996.

[12] National Statistical Office [Malawi] and ORC Macro, Malawi Demographic and Health Survey 2000, Zomba, Malawi and Calverton, National Statistical Office and ORC Macro, Maryland, Md, USA, 2001. 


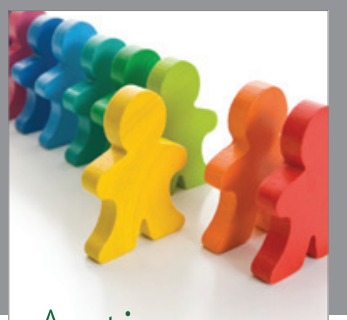

Autism

Research and Treatment
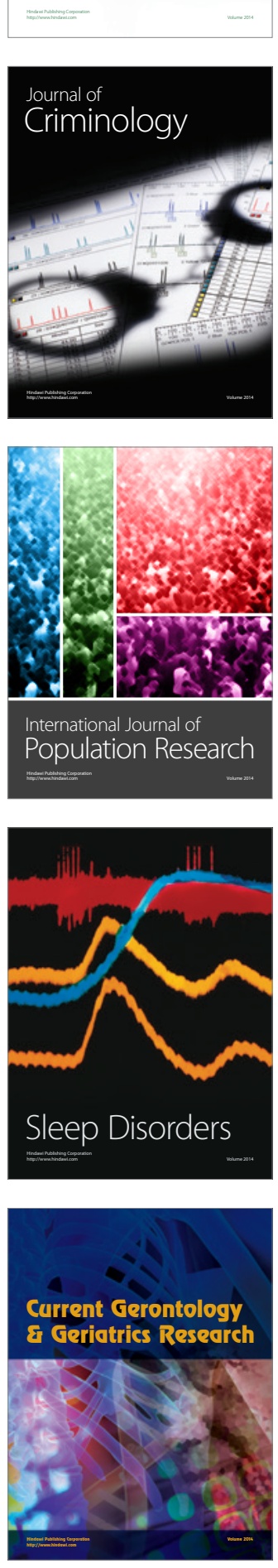
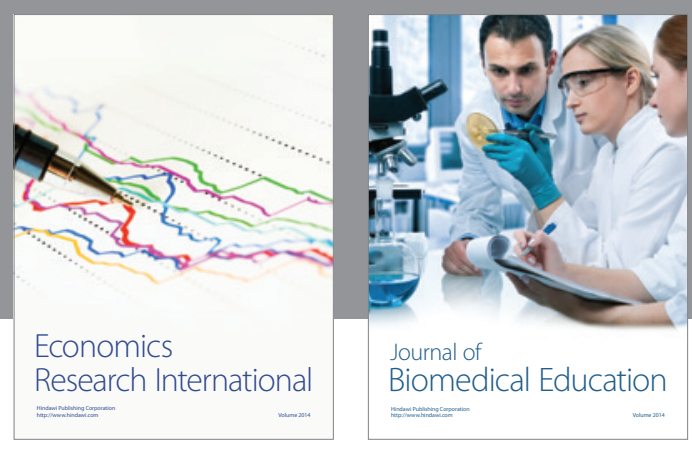

Journal of

Biomedical Education

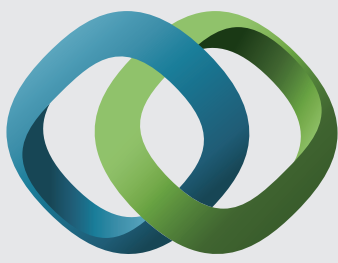

\section{Hindawi}

Submit your manuscripts at

http://www.hindawi.com
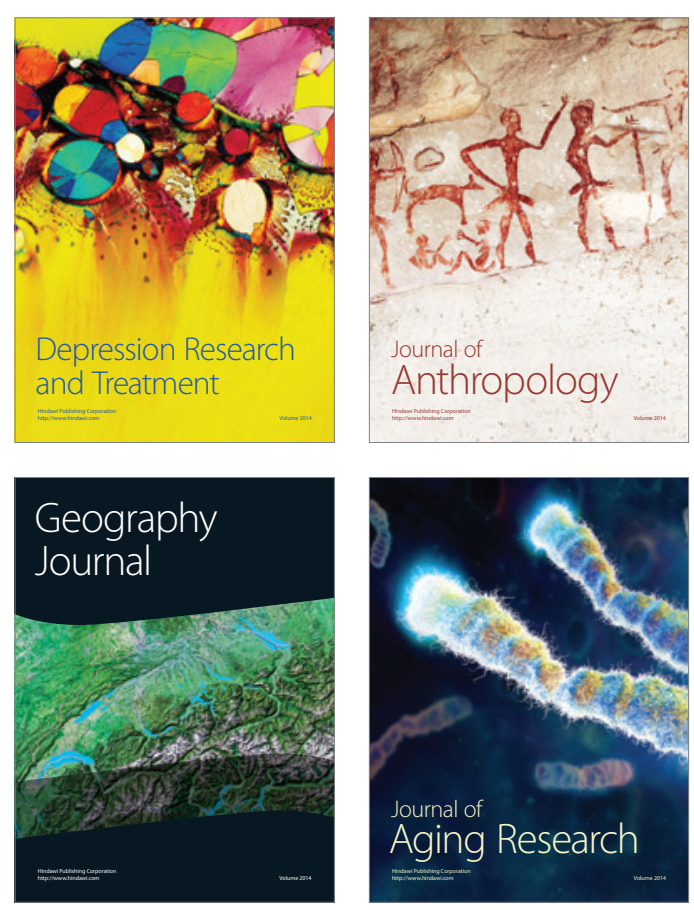

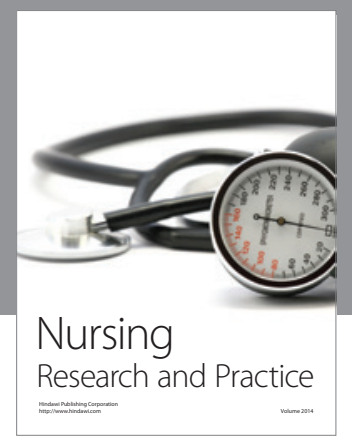

Nursing

Research and Practice

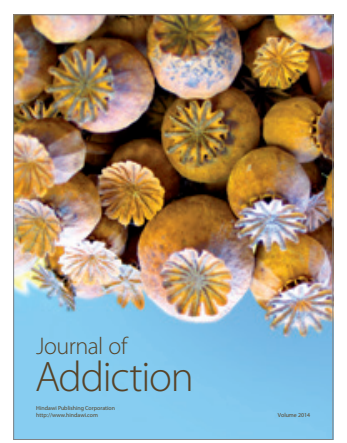

Child Development

Research

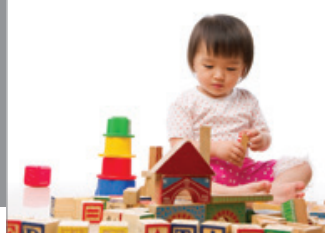

迥
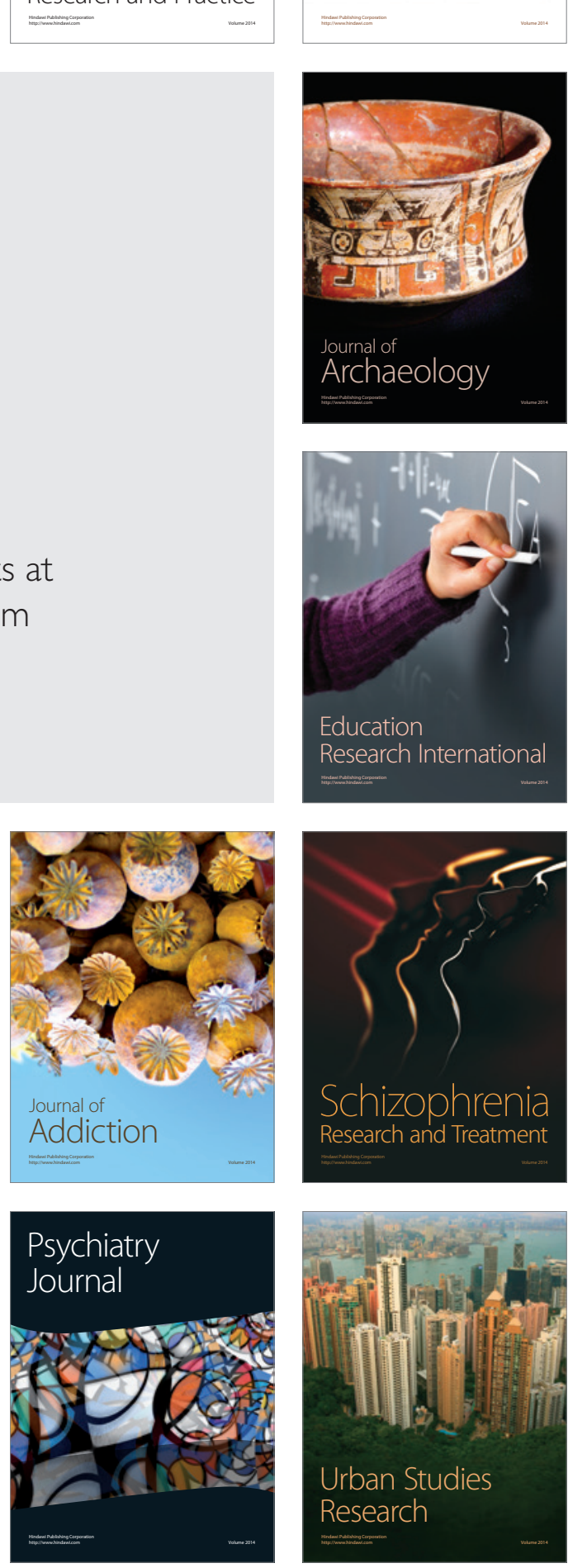